\title{
La enfermería femenina del área de medicina del Hospital de las Cinco Llagas de Sevilla en los siglos XVI al XVIII
}

\section{Female Nurses in the Medicine Area of the Hospital de las Cinco Llagas in Seville in the XVI and XVIII Centuries}

\author{
Paula Ermila Rivasplata Varillas \\ Universidad Pablo de Olavide de Sevilla
}

Fecha de recepción: 11.06.2014

Fecha de aceptación: 08.09.2015

\section{RESUMEN}

En el Antiguo Régimen ibérico, los hospitales fueron de las pocas instituciones que se caracterizaron por la especialización del trabajo femenino, convirtiéndose en lugares de refugio y de opción de vida para muchas mujeres que demostraban dedicación absoluta al hospital. En este contexto, la hipótesis planteada es que en un hospital regido por religiosos como fue el de las Cinco Llagas de Sevilla, se esquematizó el trabajo femenino del cuidado, caracterizado por el control, la prohibición y la separación de sexos. De tal manera que creó un reducto cerrado de la visibilidad pública de las labores realizadas por las enfermeras en una institución amparada por la Iglesia. La metodología utilizada fue la heurística y la hermenéutica de las fuentes primarias consultadas en el Archivo de la Diputación Provincial de Sevilla.

PALABRAS CLAVE: enfermeras, mujeres, Antiguo Régimen, Hospital de las Cinco Llagas, Sevilla

\section{ABSTRACT}

In the Iberian Old Regime, hospitals were among the few institutions that were characterized by specialization of women's work where the female nurse could develop freely, and they became places of refuge and life choice for many women who showed absolute dedication to the hospital. In this context, the raised hypothesis is that, in a hospital governed by religious as it was that of las Cinco Llagas of Seville, it was outlined the feminine work of the care, characterized by the control, the prohibition and the separation of sexes. In such a way that this hospital sheltered ill women and needed other women to work both in domestic and medical activities, creating a place closed to public visibility of the job done by these women in an institution protected by the church. The methodology used was heuristics and hermeneutics of primary sources consulted in the Archivo de la Diputación Provincial of Seville.

KEY WORDS: nurses, women, Old Regime, Hospital de las Cinco Llagas, Sevilla 
El objetivo de este artículo ha sido conocer la evolución del trabajo desempeñado por enfermeras en un hospital de fundación privada, regido por un patronato eclesiástico durante los siglos XVI al XVIII. La hipótesis que se plantea es que este hospital, regido por religiosos esquematizó el trabajo femenino del cuidado, caracterizado por el control, la prohibición, la separación de sexos que impuso el Concilio de Trento. Sin embargo, esto no fue óbice para que en un mundo de reclusión, ajeno a la competencia masculina, pudiese desarrollarse un mundo laboral femenino a semejanza del masculino en cuanto a la existencia de aprendizaje, posibilidades de ascenso, salario y jubilación. La pretendida impermeabilidad de esta área femenina al mundo externo no fue impedimento para que parte del desarrollo de la medicina sevillana de la llustración se filtrara a la enfermería a través de los médicos.

Es necesario remarcar que este trabajo sólo trata de las enfermeras que se ocupaban de enfermedades comunes y no contagiosas que atendían en la enfermería de medicina, llamada de san Pedro. Esta área estaba bajo la responsabilidad de la enfermera mayor por lo que también se la denominaba "madre de sala", aunque también se la conoció como "madre de calenturas" desde la segunda mitad del siglo XVI a comienzos del XVII".

\section{LA EVOLUCIÓN DE LA ENFERMERÍA FEMENINA}

La participación de las mujeres en la atención de las peregrinas y enfermas estaba bastante consolidada en la Edad Media y tuvo un gran impulso con el surgimiento de las órdenes mendicantes en las ciudades medievales desde el siglo XII (dominicos, franciscanos, carmelitas y agustinos) ${ }^{2}$. Mujeres con votos o sin ellos trabajaron en los hospitales como las religiosas de san Jerónimo, las hermanas del Hotel-Dieu de París y otras anónimas llamadas hospitalarias y donas. También, las mujeres participaron activamente como terciarias y beguinas, que eran formas intermedias de vivir la religión entre religiosa y seglar. En Flandes, norte de Francia y sur de Alemania, las beguinas que no estaban bajo el control del clero se dedicaron a cuidar pobres y enfermos desde el siglo XII, viviendo cerca de hospitales $^{3}$. En Valencia, las beatas o beguinas estuvieron encargadas de la enfermería femenina del Hospital de Santa María o llamado vulgarmente dels beguins (1334) ${ }^{4}$. Así también, un importante movimiento femenino laico religioso conformado por beatas y terciarias, especializado en la atención al enfermo, se desarrolló en Córdoba entre 1363 y $1460^{5}$. Cada vez más mujeres laicas de ferviente celo religioso se fueron incorporando paulatinamente en las órdenes de san Francisco y santo Domingo, como terciarias que trabajaban en hospitales ${ }^{6}$.

1 Archivo de la Diputación Provincial de Sevilla (en adelante, ADPS), Inventario de 1604, leg. 1A.

2 M. L. Martínez Martín y E. Chamorro Rebollo, Historia de la enfermería. Evolución histórica del cuidado enfermero, Barcelona, Elsevier, 2011.

3 R. Tey i Freixa, “Una aproximación a la enfermería medieval: el hospital d'en Colom en el año 1375”, en I Congreso Nacional de Historia de la Enfermería. Libro de ponencias y comunicaciones, Barcelona, Fundación Uriach 1838, 1996, p. 91.

4 F. Hernández Martín, Historia de la enfermería en España: Desde la Antigüedad hasta nuestros días, Madrid, Síntesis, 1996, p. 93; Ch. M. Frank y T. Elizondo, Desarrollo histórico de la enfermería, México, La Prensa Médica Mexicana, 1981, pp. 118-119.

5 M. del M. Graña Cid, "Mentalidades femeninas y propuestas de reforma religiosa en la Castilla bajomedieval (Observaciones sobre las políticas del movimiento religioso femenino)", en Trabajo, creación y mentalidades de las mujeres a través de la historia. Una visión interdisciplinar, Valladolid, Universidad de Valladolid, 2011, p. 98.

6 M. M. Rivera Carretas, "Las beguinas y beatas, las trovadoras y las cátaras: el sentido libre de ser mujer", 
Asimismo, el siglo XIII significó el surgimiento de las universidades que formaron "físicos" como fueron llamados los médicos por aquel entonces ${ }^{7}$. El ejercicio de la medicina medieval fue reduciéndose, al prohibirse que lo ejercieran personas que no se hubiesen formado académicamente. Los monjes dejaron de hacerlo ${ }^{8}$, pero muchas personas aún lo hacían, entre ellas mujeres sanadoras ${ }^{9}$. Al hacer oídos sordos a las advertencias y restricciones, las instituciones patriarcales descargaron sobre ellas persecuciones, principalmente en el centro y norte de Europa ${ }^{10}$. Sanadoras que trabajaban de forma independiente fueron perseguidas, pero no a las que trabajaban cuidando en instituciones hospitalarias, amparadas por la Iglesia. Por ejemplo, en el norte de España, específicamente en Navarra, dicho siglo XIII significó un gran salto del trabajo de la mujer en los hospitales ibéricos, pasando del servicio de limpieza, lavado y cocina a la labor asistencial. Una prueba de lo anteriormente remarcado lo encontramos en el Hospital de Roncesvalles en 1127, en donde el cargo de la condimentación de la comida y del arreglo de la ropa recaía en beatas o religiosas. Pero, un siglo después, el mencionado hospital ya disponía de salas de enfermerías divididas por sexos: una para hombres y otra para mujeres, atendida esta última por personal femenino. Lo mismo ocurría en otros hospitales del norte de la Península Ibérica, como el Hospital de San Miguel de Pamplona donde había presencia femenina asistencial: enfermeras, laicas o religiosas, en $1293^{11}$.

Lo que de facto ocurría en los hospitales, terminó concretizándose en las constituciones de dos de ellos, el de San Antolín de Palencia y el Hospital de la Santa Creu en Barcelona. En las constituciones de ambos hospitales se encuentran las primeras menciones de las responsabilidades del personal femenino asistencial hospitalario en España dentro del marco de la moderna organización hospitalaria que se abrió paso a finales del XIV. Así, en 1398, el Hospital de San Antolín de Palencia en el reino de Castilla se encontraba institucionalizando la participación femenina en los hospitales en la figura de la enfermera mayor, las enfermeras menores, la madre de niños, cocineras y lavanderas en sus Instrucciones para la gobernación del Hospital de San Antolín y lo que cada uno es obligado a hacer en su oficio ${ }^{12}$. En 1417, el Hospital de la Santa Creu de Barcelona incorporó en sus nuevas constituciones a las donas de las enfermas y las donas de los niños.

En el siglo XV, casi todos los hospitales que atendían a mujeres destacan en sus constituciones a la mujer enfermera, como es el caso del Hospital San Juan Bautista de

en I. Morant (dir.), Historia de las mujeres en España y América Latina de la Prehistoria a la Edad Media, vol. I, Madrid, Ediciones Cátedra, 2006, p. 752.

7 L. García-Ballester y J. Arrizabalaga, "El médico en la Edad Media", en El médico de familia en la historia, Madrid, Doyma, 1999, pp. 35-47.

8 P. Laín Entralgo, La amistad entre el médico y el enfermo en la Edad Media, Madrid, Real Academia de Historia, 1964; Historia de la Medicina, Barcelona, Salvat editores, 1978, p. 191. La prohibición de los clérigos para ejercer la medicina se dio desde el Concilio de Clermont de 1130 y se reiteró en los concilios de Reims (1131), Londres (1138), Letrán (1139), Montpellier (1162 y 1195), Tours (1163) y París (1212).

9 S. Federici, Calibán y la bruja. Mujeres, cuerpo y acumulación originaria, Madrid, Traficantes de Sueños, 2010, pp. 275-284.

10 T. Vinyoles Vidal, "Hilar, cocinar, cuidar, cultivar, curar, educar, amar... quehaceres de las mujeres medievales", en Trabajo, creación y mentalidades de las mujeres a través de la historia. Una visión interdisciplinar, Valladolid, Universidad de Valladolid, 2011, p. 93. Tras la oficialización de los estudios universitarios, las mujeres se vieron apartadas de tareas que realizaban desde tiempos ancestrales como la medicina.

11 C. Eseveri Chavarri, Historia de la enfermería española e hispanoamericana, Madrid, Editorial Universitas, 1995, p. 23. Una persona dejó dinero a través de su testamento para alimentar a las enfermeras religiosas del Hospital de San Miguel en 1309, indicándonos su existencia.

12 C. Eseveri Chavarri, Historia de la enfermería española e hispanoamericana..., pp. 28-29. 
Guadalupe, en el que se menciona la sección femenina atendida por beatas. De esta manera, la labor asistencial de la mujer era aceptada y común en la Baja Edad Media, a pesar que la imagen y consideración social de la mujer sanadora había empeorado notablemente, en un proceso gradual de degradación que coincidió con el desarrollo institucional del ejercicio de la medicina y con el resurgimiento de tradiciones intelectuales misóginas ${ }^{13}$.

A partir de la Contrarreforma, la actitud que muestra la Iglesia en cuanto a las mujeres es de mayor control, físico e intelectual, pero esta vez apoyada por un proceso enseñanzaaprendizaje premeditado, con el fin de interiorizar en sus personas los objetivos de la Iglesia y priorizarlos a los personales. De esta manera, las instituciones regidas por la Iglesia, como algunos hospitales, se convirtieron en verdaderos centros de formación religiosa y de enseñanza de oficios relacionados con el cuidado y otras actividades necesarias para su buen funcionamiento, dirigidos tanto a hombres como mujeres, clérigos y laicos. La Iglesia se volcó más a la sociedad y sobre todo a la mujer, por ser eje principal en la familia en el proceso de enseñanza de las tradiciones a las nuevas generaciones ${ }^{14}$.

El Concilio de Trento, fruto de la Contrarreforma católica, enfatizó la reclusión de las mujeres en los conventos y en toda institución civil bajo el amparo de la Iglesia. Como bien indica Perry, "el enclaustramiento de la Contrarreforma llevó a la doctrina de las esferas separadas para hombres y mujeres" ${ }^{15}$. Así, la presencia femenina en los hospitales se controló aún más, según las distintas constituciones hospitalarias. En estas normativas, la separación física de la enfermería masculina y femenina y la separación de funciones entre el enfermero y la enfermera no eran nuevas, pero sí más tajantes, imponiendo el torno para la entrega de la comida y las medicinas. El acceso al área femenina era a través de una puerta con dos llaves diferentes. Una la tendría el hermano mayor o el administrador y la otra la madre enfermera o la madre mayor y dicha puerta sería de acceso restringido sólo a enfermas. El médico, cirujano, barberos y boticarios accedían al área femenina en horario de visitas reglamentadas o cuando se les requería para hacer sangrías y entregar medicinas. Asimismo, sólo un sacerdote conocido como el semanero, tenía entrada irrestricta a la zona de mujeres. Un cargo rotativo entre los curas del hospital. De esta manera, la reclusión se impuso sobre las mujeres religiosas y laicas que trabajaban en hospitales bajo amparo eclesiástico con el objetivo de cumplir la imposición de reformas más contundentes en cuanto a la disciplina, recato y honor.

13 M. Cabré i Pairet, "Como una madre, como una hija: las mujeres y los cuidados de salud en la Baja Edad Media", en I. Morant (dir.), Historia de las mujeres en España y América Latina de la Prehistoria a la Edad Media, Madrid, Ediciones Cátedra, 2006, pp. 637-657; J. Dangler, Mediatin Fictions: Literature, Women Healers, and the Go-Between in Medieval and Early Modern Iberia, Lewinsburg, Bucknell University Press, 2001; F. Salmón y M. Cabré, "Fascinating Women: The Evil Eye in Medical Scholasticism", en Medicine from the Black Death to the French Disease, Aldershot, Ashgate, 1998, pp. 53-84.

14 E. Schultz Van Kessel, "Vírgenes y madres entre el cielo y tierra. Las cristianas en la primera Edad Moderna", en G. Duby y M. Perrot (eds.), Historia de las mujeres en Occidente. Del Renacimiento a la Edad Moderna, Madrid, Taurus, 1992, p. 205. La aplicación de los decretos del Concilio de Trento aportó cambios profundos en los conventos, pues funcionaron cada vez más abiertamente en beneficio de la política eclesiástica central. Por ejemplo, algunos proporcionaron instrucción básica a niñas.

15 M. E. Perry, Gender and Disorder in Early Modern Seville, Princeton, Princeton University Press, 1990, p. 177. La preocupación por la moralidad es lo que caracterizó la Contrarreforma y marcó la literatura, las leyes y las regulaciones civiles. Se dio máximo valor a la teología de la pureza a través de símbolos tan poderosos como la Virgen. Para proteger la pureza de lo profano se buscó la reclusión ya no sólo religiosa sino civil de la mujer en el convento, hogar, etcétera. La mujer libre y errante traía deshonor. Sin embargo, algunas reclusiones femeninas permitieron mayor libertad en sus recintos. 


\section{LAS ENFERMERAS DEL HOSPITAL DE LAS CINCO LLAGAS DE SEVILLA}

A comienzos del siglo XVI, en Sevilla, el Hospital de las Cinco Llagas, conocido popularmente como la Sangre, fue fundado por doña Catalina Ribera y Mendoza, esposa de don Pedro Enríquez, IV Adelantado Mayor de Andalucía ${ }^{16}$. Este hospital estuvo destinado a mujeres pobres enfermas, cuyas dolencias no fuesen incurables ni contagiosas. Se recibía a enfermas con calenturas, diarreas, abscesos, úlceras y, también, las que tenían heridas, fracturas y dislocaciones ${ }^{17}$. Doña Catalina dotó al hospital con un cuantioso patrimonio y obtuvo la licencia del Papa Alejandro VI a través de las bulas de 1500 y 1502. También otorgaron otras bulas Clemente VII y Julio III en 1524 y 1549 respectivamente, por las que este hospital obtuvo el privilegio de la exención de la jurisdicción ordinaria ${ }^{18}$.

En la primera mitad del siglo XVI, la matrona fue la mujer designada por el hospital para el cuidado de las enfermas, atendiéndolas según indicación del médico y cirujano, ayudada de criadas y esclavas. Además se ocupaba de que la botica estuviese aprovisionada de los medicamentos necesarios que suministraba un boticario externo al hospital. También era su responsabilidad que el almacén y la despensa estuviesen abastecidos por el despensero y botiller ${ }^{19}$.

Según el primer reglamento de este hospital realizado en 1503, la matrona se ocupaba de quince enfermas. En 1506 a esta mujer se la denomina enfermera. En 1528, se menciona a la enfermera llamada Isabel Bueno, a una moza de enfermería, a una mujer de servicio y a una donada. Todas estas mujeres trabajaban en la enfermería del hospital. Posteriormente, en 1546 se menciona, por vez primera, a una enfermera mayor y dos enfermeras ${ }^{20}$. En 1559, al trasladarse el hospital a un nuevo y amplio edificio renacentista mandado construir por el hijo de la fundadora, don Fadrique Enríquez de Ribera, aumentó el número de ayudantes de enfermería y las tres enfermeras menores se pasaron a denominar "mozas de enfermería"21. Esta área necesitaba de mucha mano de obra, por lo que en 1562 ya había cinco mozas de enfermería.

Encontramos en los libros capitulares que a comienzos del siglo XVII, el hospital tenía varias áreas, una para enfermas, otra para heridas, y dos más para agonizantes y

16 ADPS, Constituciones del Hospital de las Cinco Llagas de Sevilla de 1624, folio 1 r.

17 D. López Falante y M. de la P. de la Torre Liébana, "El Hospital de las Cinco Llagas de Sevilla: un modelo de organización de instituciones de beneficencia durante el Antiguo Régimen", Archivo Hispalense, 237 (1995), pp. 61-77; ADPS, Constituciones del Hospital de las Cinco Llagas de Sevilla de 1624, artículo 4 y Constituciones del Hospital de las Cinco Llagas de Sevilla de 1734, artículo 10.

18 J. I. Carmona García, "Cinco siglos de historia: trayectoria institucional y asistencial del Hospital de la Sangre", en El edificio sede del parlamento de Andalucía. El Hospital de las Cinco Llagas, Sevilla, Parlamento de Andalucía, 2007, p. 81. El hospital dependía de la autoridad papal; F. Collantes de Terán Caamaño, Los establecimientos de caridad de Sevilla, Sevilla, Colegio Oficial de Aparejadores y Arquitectos Técnicos de Sevilla, 1980, pp. 131-133. Este hospital recibió privilegios; ADPS, leg. 4B. Los autos capitulares de este Hospital de la Sangre (1716 -1734), folio 78r (1727).

19 ADPS, leg. 1A. Constitución del Hospital de las Cinco Llagas de 1503. "Y mandamos asimismo al mayordomo del dicho hospital que compre y gaste todo lo que la tal mujer le encomendare y mandare que sea para el proveimiento del dicho hospital y personas de él. A la cual dicha mujer encargamos y cometemos que tenga a su cargo toda la ropa de camas y botica de enfermería y fuego de cocina e de toda la casa y lo mande reparar y guardar y proveer y tratar y servir como viere que cumple sobre lo cual en cuanto en nos es le encargamos la conciencia y le damos todo nuestro poder cumplido la cual sea obligada a recibir todas las cosas por inventario y dar cuenta por el mismo y jurar como lo tendrá y tratará y acrecentará en provecho del dicho hospital de las enfermas de él, según que le fuere de mandado".

20 ADPS, Libro de "Recibo y Gasto", leg. 106. "La enfermera mayor ganaba 3.268 maravedíes y las dos enfermeras 2.448 maravedíes cada una".

21 ADPS, Libro de "Recibo y Gasto" (1559), leg. 107. 
convalecientes. Realidad que no se menciona aún en el segundo reglamento del hospital, el de 1603, pero sí en el de $1624^{22}$. Cada área tenía su propia asistenta con sus ayudantes. La matrona, entonces llamada madre mayor, sólo se dedicaba a la administración de la enfermería femenina del hospital, es decir, a mantener el orden, disciplina y el correcto funcionamiento de su área, delegando sus funciones curativas a las distintas responsables de cada sala.

La madre mayor, que era la jefa del área femenina del hospital, asignaba a la madre enfermera cinco doncellas de dote para que le ayudasen en la asistencia y cuidado de las enfermas, según Constitución de $1624^{23}$. La madre enfermera tenía el deber de ejercer funciones docentes con sus ayudantes, "enseñándolo a hacer por su persona" la manera de tratar, cuidar, medicar y aplicar unciones a las enfermas, tal como disponía el médico ${ }^{24}$. Sin embargo, durante la etapa de 1620 a 1639, la madre enfermera y sus doncellas cuidaron no sólo a las enfermas de calenturas, convulsiones sino también convalecientes e incurables. Esto se hizo mientras estaban estableciendo las últimas áreas mencionadas, nacidas de las generosas donaciones testamentarias de ese periodo que los patronos del hospital trataron de organizar y administrar ${ }^{25}$. Después de este periodo, la madre enfermera y sus cinco criadas volvieron a ocuparse solamente de las enfermas de la sala de enfermería, llamada san Pedro.

En el siglo XVIII, ya estaban configuradas las funciones de la madre enfermera, las que eran, además de las mencionadas, estar presente durante la visita del médico y tomar cuenta de los medicamentos que mandaba a cada enferma, avisar al barbero cuando se le requería y dar aviso a la cocinera de las raciones del día según cada paciente. Era la que distribuía los consuelos o "regalos" entre las enfermas de su sala, en forma de bizcochos, azúcar, pasas y nueces que le entregaba la madre mayor y que guardaba en un escaparate de la sala que estaba a su cargo. El objetivo de la entrega de estos dulces era halagar, mimar y consolar a las enfermas ${ }^{26}$. Otra de sus funciones era mantener el silencio necesario para el descanso de las enfermas en su enfermería. También, la madre enfermera era responsable del registro y vigilancia de los familiares durante las visitas a las enfermas para que no introdujeran comida alguna del exterior, a excepción que considerase que la comida traída no causaba inconveniente alguno a la curación de la enferma.

La madre enfermera coordinaba la limpieza, lavado, cocina, ropería y la administración de la enfermería femenina y daba protección, mimos, reprimendas, guía, no sólo a los enfermos, sino también a las jóvenes aprendices, sirvientas, etcétera. El trabajo realizado

22 ADPS, Constitución de 1603 y Constitución de 1624, leg. 1A.

23 P. E. Rivasplata Varillas, Doncellas de dote del Hospital de las Cinco Llagas de Sevilla. Una lectura en clave de género, Berlín, Editorial Académica Española, 2011, pp. 1-345.

24 Biblioteca Colombina (en adelante, BC), Constituciones y ordenanzas del Hospital de las Cinco Llagas de 1734, Fondo Gestoso, Papeles varios, tomo V, const. 109 de la enfermera mayor, const. 110. Acuerdo de 1657, folio 227r. Acuerdo de 1733, folio127r.

25 ADPS, Libro de juntas capitulares (1616-1637), leg. 4B, folios 21r-v, 23r-v y 14r (1620). Doña María de Torres, mujer del jurado Gaspar de Ávila Alvasajado, dotó con 20.000 ducados para veinte camas asignadas al área de incurables en 1620; Libro capitular (1637-1658), leg. 4B, folio 9v; Escritura y protocolo del Patronato de Convalecientes (1622), libro 9. El tesorero de la Casa de la Moneda de Sevilla, Diego Yanguas, fundó la convalecencia del hospital.

26 M. del C. Gómez García, "Trabajo y actividades de las religiosas en los conventos malagueños (siglo XVIII)", en M. Matilla y M. Ortega (eds.), El trabajo de las mujeres: siglos XVI-XX, Madrid, Universidad Autónoma de Madrid, 1996, p. 113. Sobre este punto, llama la atención la semejanza con las monjas enfermeras en los conventos de clausura, las que tenían confituras en las alacenas para consolar a las monjas enfermas junto con las medicinas a suministrar a cada una, cumpliendo todo lo que el médico le hubiese ordenado. 
por la enfermera mayor era de los más dificultosos y exigentes. Motivo por el cual, alguna madre enfermera solicitaba ser cambiada de área y ser destinada a otra, alegando como justificación que los "calores de los anafes" (servir la comida), perjudicaban su salud27. Así, el área de enfermería solía ser destinada a madres relativamente jóvenes y si eran las adecuadas se quedaban muchos años en ese cargo hasta jubilarse.

Es interesante indicar que cuando las enfermeras del hospital se encontraban en posición de tomar decisiones en cuanto a la salud de las enfermas, lo hacían con total libertad. Cosa que ocurría en tiempos de emergencia, epidemias, guerras, crisis de subsistencias, inundaciones y cuando había pocos médicos y cirujanos o no cumplían con sus obligaciones. Cuando se volvía a la normalidad eran detenidas por mandato superior. Por ejemplo: a mediados del siglo XVII, en 1679, el médico tomó por costumbre realizar visitas irregulares y a destiempo ${ }^{28}$, así que las madres tomaron decisiones propias en cuanto a determinar purgas y ciertos medicamentos hasta 1681, que se volvió a regular, prohibiéndose determinantemente que lo hicieran sin consultar con el médico. Sin embargo, las madres enfermeras ya se habían acostumbrado a tomar decisiones propias en las enfermerías presentándose problemas de intersección de competencias con el nuevo médico. De esta manera en 1681, los patronos determinaron que la madre enfermera no se entrometiese en funciones que atañían al médico.

Que las enfermas no se les dé de beber hasta que venga el médico, para que consultado con él diga a quien se le debe dar, o, no, dicha bebida que se tenga mucho cuidado en ejecutar todo lo que ordenare en las visitas dicho médico, y que para mudar las enfermas de una cama a otra, o a otro cuarto sea con el parecer de dicho médico y no de otra manera; y que la madre mayor no se entrometa en esto porque sólo ha de hacerlo dicho médico a quien toca. Que la madre enfermera por las mañanas y tardes consulte con dicho médico y enfermas para saber cómo apetecen la comida y en esa conformidad se les dé29.

Sin embargo, las madres lograron que el médico de este hospital "cumpla con las obligaciones de su oficio, y no se entrometa en aquello que no le toca"30.

En total hubo aproximadamente ochenta y seis madres enfermeras en este hospital en el Antiguo Régimen, tal como indica a continuación la tabla número 1.

27 ADPS, Peticiones a los patronos de hospital (1666-1825), leg. 89B.

28 ADPS, Libro de juntas o actas capitulares (1659-1687), leg. 4B, folio 153v (1679). Por lo que fue despedido en 1679 debido a que por "más de un mes que no acude al hospital para visitar dichas enfermas enviando a un médico en su nombre algunos días y después ninguno [...]"

29 ADPS, Libro de juntas (1681), leg. 4B, folio 167r-v.

30 ADPS, Libro de juntas (1680), leg. 4B, folio 161 r. 
Tabla 1. Madres enfermeras del Hospital de las Cinco Llagas (1503-1836). Desde 1503 a 1551, enfermeras sin identificación, ni datos, salvo algunas excepciones.

\begin{tabular}{|c|c|c|}
\hline Siglo XVI & Siglo XVI & Siglo XVIII y XIX \\
\hline $\begin{array}{l}\text { - María torres (1551-1553) } \\
\text { - Juana (1554) } \\
\text { - María de la O (1555-1556) } \\
\text { - Suárez (1557) } \\
\text { - Ana Bernal (1560) } \\
\text { - Isabel Fernández (1561) } \\
\text { - Ana Jiménez (1562) } \\
\text { - Zamora (1563) } \\
\text { - Beatriz de Aguilera (1564) } \\
\text { - Isabel Rodríguez } \\
\text { (1565-1566) } \\
\text { - Leonor López (1567) } \\
\text { - Bernal (1569) } \\
\text { - María de esperanza (1571) } \\
\text { - Juana Beltrán (1572) } \\
\text { - María Suárez (1573-1576) } \\
\text { - Ana María Salas (1580) } \\
\text { - Elvira Sánchez } \\
\text { (1582-1584) } \\
\text { - Leonor Rodríguez(1585) } \\
\text { - María de la Cruz (1587) } \\
\text { - Juana Baptista (1588) } \\
\text { - Ana García de la } \\
\text { Concepción (1589) } \\
\text { - Violante de Jesús (1591) } \\
\text { - Catalina de los Palacios } \\
\text { (1592) } \\
\text { - María de la Encarnación } \\
\text { (1593) } \\
\text { - Elvira Sánchez (1594) } \\
\text { - Leonor Núfiez (1595-1596) } \\
\text { - Leonor de Villalobos } \\
\text { (1598) } \\
\text { - María Cortes (1599) }\end{array}$ & 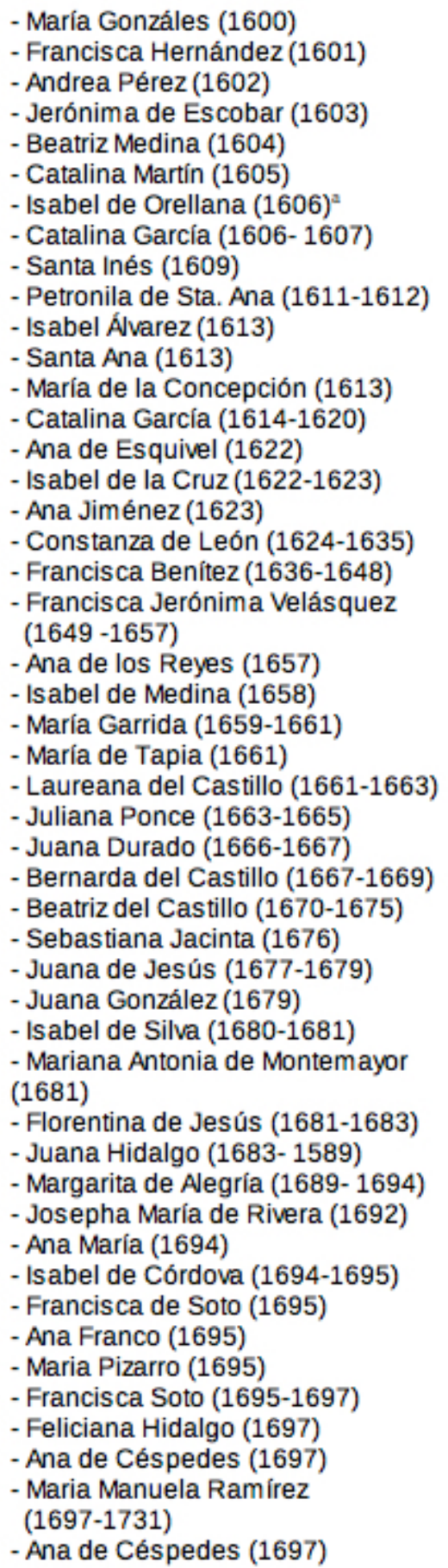 & $\begin{array}{l}\text { - Maria Manuela Ramírez } \\
\text { (1697-1731) } \\
\text {-Juana del Castillo Coronel } \\
\text { (1731-1736) } \\
\text { - Maria Bernal (1736-1757) } \\
\text { - Catalina de Arias (1757-1764) } \\
\text { - Maria Márquez (1764-1765) } \\
\text { - Juana Moscoso (1772-1774) } \\
\text { - Josefa Doyo (1774) } \\
\text { - Gertrudis Molina (1775) } \\
\text { - Isabel Rodriguez (1807-1830) } \\
\text { - María de los Reyes Olmedo } \\
\text { (1826) } \\
\text { - Antonia García (1826) }\end{array}$ \\
\hline
\end{tabular}

(a) ADPS, Autos capitulares (1584-1635), leg. 4A, folios 60v y 71v (1606). "Mandaron sus patronos que la madre de sala doña Isabel de Orellana se vaya a su casa y no haga el oficio de aquí adelante [...] le entregaron ayuda de costa para que se vaya a su tierra".

(b) ADPS, Libro de defunciones de enfermas, Libro 106. Isabel Rodríguez obtuvo el título de madre jubilada por haber servido muchos años de enfermera mayor en este hospital, murió a los ochenta y tres años. Era soltera.

Fuentes: Libro recibo y gasto (1691-1696), leg. 125; Libros salarios, legs. 187 y 188. 
Las madres enfermeras del Hospital de las Cinco Llagas de Sevilla

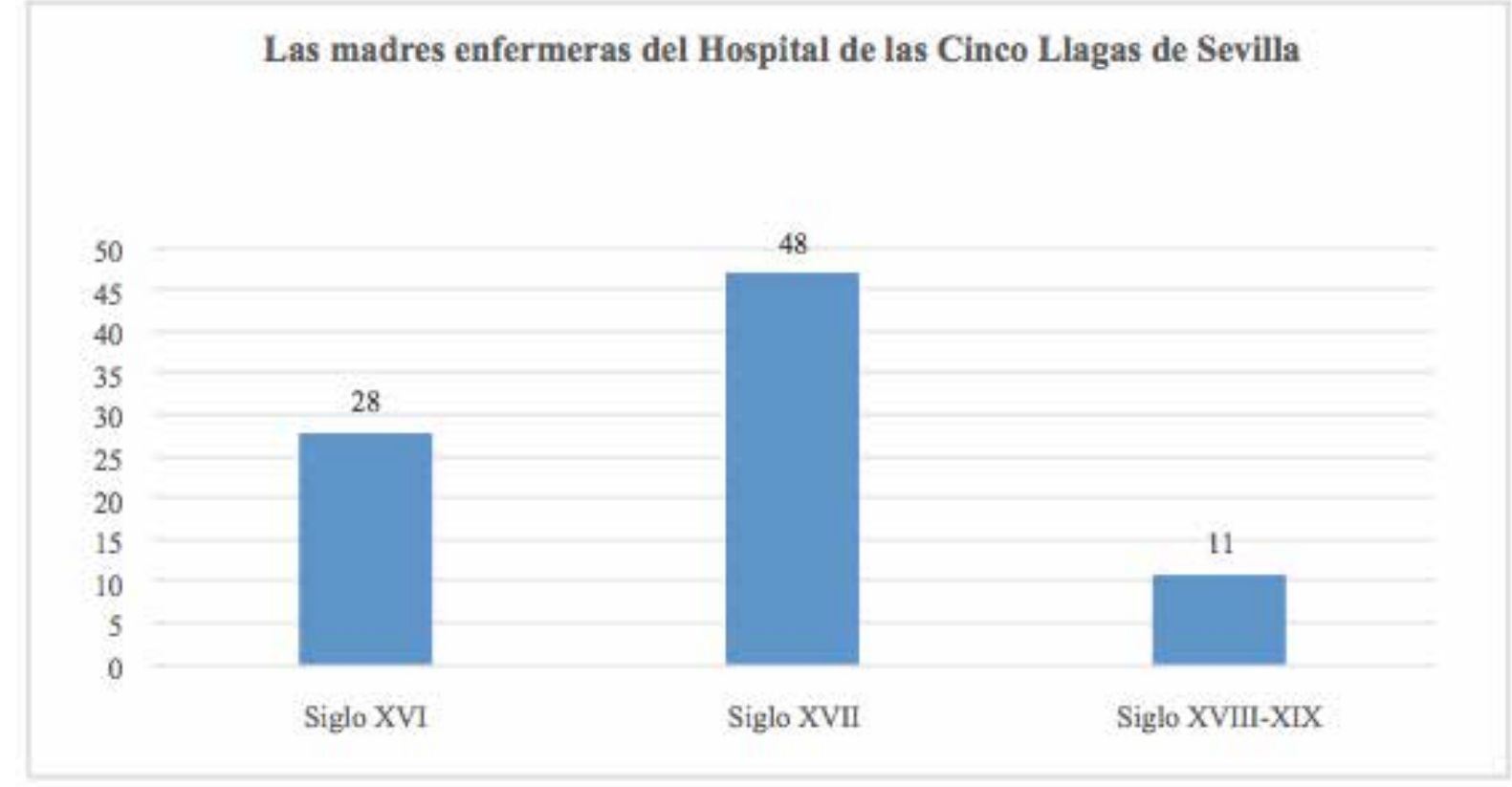

Los datos del siglo XVI no están completos. En el siglo XVII, las madres enfermeras no permanecieron mucho tiempo en sus cargos a diferencia del siglo XVIII. En el periodo 1697 a 1757, las enfermeras se caracterizaron porque estuvieron muchos años consecutivos ocupando el cargo. De entre todas, destacaron María Manuela Ramírez que trabajó desde 1697 a 1731, es decir, treinta y cuatro años, le siguió María Bernal desde 1736 a 1757, veintiún años, e Isabel Rodríguez (1807-1830), veintitrés años. Generalmente, las madres enfermeras permanecían de uno a dos años en los tres siglos que duró el cargo. El por qué estuvieron más tiempo las madres enfermeras en sus cargos en el siglo XVIII fue debido a que coincidieron mujeres eficientes que los ejercieron por largo tiempo.

\subsection{Acceso de las enfermeras al hospital}

Este hospital prefería viudas o solteras para que ejercieran el cargo de enfermeras. Es decir, personas solas, sin familia a quien cuidar ni dependencias que atender, para que puntualmente cumplieran con sus tareas en el hospital ${ }^{31}$. Evidentemente, no se podía recurrir a mujeres casadas, pues estaban bajo la tutela de sus maridos, siendo proveedoras de servicios de apoyo, mayoritariamente no remunerados en el seno de la familia, ya que la sociedad en el Antiguo Régimen se regía por el corporativismo familiar. Aunque sí se recibían casadas sin familia, solas, cuyos maridos estuviesen en las Indias o en cualquier parte del mundo.

Los patronos buscaban enfermeras que fuesen eficientes en sus cargos y que respondiesen con lo que esperaban de ellas, en caso contrario, eran removidas a otros oficios hasta que encontraran el idóneo donde estabilizarse. Si fracasaban eran despedidas o se retiraban ellas mismas. De esta manera, se necesitaría tiempo y muchos cambios para detectar enfermeras eficaces.

31 ADPS, Libro de juntas capitulares (1616-1637), leg. 4B, folio 80r (1631). Sin embargo, se ha encontrado que algunas madres habían tenido hijos, testificados en sus testamentos. Incluso, una madre enfermera, Constanza de León, pidió ayuda para el casamiento de su hija en 1631. 
Las mujeres que trabajaban en el hospital eran rotadas en las diferentes áreas del sector femenino, a excepción de algunas enfermeras que habían demostrado eficiencia. Una vez detectadas e identificadas las mujeres con comprobada experiencia cuidadora se quedaban en el área de enfermería. Así, no es raro encontrar a enfermeras que permanecían de veintiuno a treinta y cuatro años en el cargo como Francisca Benítez (1607 a 1641), María Bernal (1736 a 1757) e Isabel Rodríguez (1807 a 1830). Otro caso fue el de la enfermera María Manuela Ramírez que entró en el cargo el 15 de octubre de 1697, permaneciendo hasta 1731. Pero antes de ella, pasaron por el oficio por breve tiempo nueve enfermeras. Sin embargo, una vez encontrada la idónea, generalmente se quedaba hasta que muriera o hasta que la jubilasen los patronos del hospital.

También accedían a este cargo las madres enfermeras que habían permanecido mucho tiempo en el hospital, desempeñando otras funciones: "[...] y siendo tan notorios a [los patronos] los méritos de la Sra. Madre da. Isabel Rodríguez que tiene cerca de diez y seis años de hospital, con el más exacto cumplimiento la nombraron para que ocupe dicha plaza de enfermera mayor [...]"32. Así, se podía obtener esa plaza por longevidad en el servicio dentro del hospital ${ }^{33}$. Se les daba un salario y ración de comida según costumbre a las personas que ejercían dicho oficio, es decir se les pagaba en dinero y en especies.

\section{EL MÉDICO: GUÍA Y TIMÓN DEL ÁREA DE ENFERMERÍA DEL HOSPITAL}

Indudablemente, el médico cumplió un papel trascendental en las actividades realizadas en el hospital, pues a partir de sus prescripciones se originaba el trabajo a realizar de todas las personas que se ocupaban de asistir a las enfermas del hospital. Los médicos eran los que guiaban el quehacer diario en la sala de medicina, al determinar las tareas que las enfermeras, boticario, sangrador, cocineras y sirvientas debían realizar para la asistencia de las enfermas. También era el que desahuciaba, delegando a la moribunda al cuidado espiritual de los curas, beatas o cualquier persona encargada del bien morir de las enfermas.

Físicos de excelente reconocimiento trabajaron en este hospital, algunos de ellos dejaron una importante huella en el desarrollo de la medicina, dejando constancia de sus conocimientos en publicaciones. En el caso del siglo XVI, no se tiene los nombres de todos los médicos que trabajaron en este hospital, al perderse la documentación primaria. De entre todos destacó el físico y cirujano Bartolomé Hidalgo Agüero.

Algunos médicos y cirujanos que trabajaban en el Hospital de la Sangre, también lo hacían en el Cardenal de Sevilla, así como eclesiásticos en diferentes cargos en ambos hospitales. La razón estaba en que compartían dos patronos que eran los priores del monasterio de santa María de las Cuevas y el monasterio de san Jerónimo del Campo.

32 ADPS, Libro de Juntas y acuerdos (1800-1835), leg. 4C. folio 65v (1807). Llegó a ser madre mayor entre 1816 a 1829.

33 ADPS, Autos capitulares (1584-1635), leg. 4A. 
Tabla 2. Relación de médicos que trabajaron en el Hospital de la Sangre en el siglo XVI.

\begin{tabular}{|c|c|}
\hline $1557-1565$ & $\begin{array}{l}\text { Médico y cirujano Martín López de la Cueva. En } 1557 \text { ganaba } 7.000 \\
\text { maravedíes anuales. En } 1559 \text {, el hospital ya se había trasladado a la } \\
\text { nueva infraestructura ubicado fuera de la muralla, en el arrabal de la } \\
\text { Macarena. Recibió } 15.000 \text { maravedíes, ocupándose sólo del área de } \\
\text { medicina porque la parte de cirugía fue designada al licenciado Alfaro } \\
\text { que recibía el mismo salario que el médico del hospitala. También } \\
\text { trabajaba en el Hospital del Cardenal. }\end{array}$ \\
\hline 1573 & $\begin{array}{l}\text { Médico Lic. León. Este nuevo galeno vio incrementado su salario a } \\
\text { casi el doble, recibiendo } 25.000 \text { maravedíes anuales, mientras que el } \\
\text { cirujano Alfaro sólo } 20.000 \text { y el barbero Antón Pérez } 9.000 \text { maravedíes. } \\
\text { Desde el } 12 \text { de enero de } 1576 \text {, el afamado cirujano doctor Bartolomé } \\
\text { Hidalgo Agüero sirvió en el hospital }{ }^{b}\end{array}$ \\
\hline $1580-1592$ & $\begin{array}{l}\text { Médico Fernando de Valdez, que también trabajaba en Hospital del } \\
\text { Cardenal, ganaba } 30000 \text { maravedíes anuales }{ }^{c} \text {. Asimismo ejercía como } \\
\text { médico y cirujano el doctor Hidalgo, recibiendo } 36.000 \text { maravedíes, } \\
\text { pero en el año de } 1582 \text { se le dio } 20.000 \text { y el doctor Valdés mantuvo la } \\
\text { cantidad que recibía de salario. El barbero no experimentaba cambio } \\
\text { alguno en su paga. }\end{array}$ \\
\hline 1593-1598 & Médico Alonso de Venegas que recibía 30.000 maravedíes anuales. \\
\hline 1599-1604 & Médico Bermudo \\
\hline
\end{tabular}

(a) A. Piñero Gálvez, "Historia de la medicina de Sevilla en los siglos XVI y XVII", en A. Hermosilla Molina, Historia de la medicina sevillana, Sevilla, Sociedad Nicolás Monardes, 1993, p.171. Entre los clínicos sevillanos que alcanzaron gran renombre en el siglo XVI se encuentra el doctor Andrés Zamudio de Alfaro. Publicó en 1568 una memoria sobre la enfermedad de las landres que tuvo éxito y se reeditó. En 1579 escribió un libro sobre viruelas y otro sobre carbuncos.

(b) Ibídem, p. 172. Bartolomé Hidalgo Agüero de Sevilla fue el más famoso cirujano de España en su época y maestro de toda una generación de cirujanos. Además escribió un libro innovador sobre cirugía y propuso el llamado método seco en el tratamiento de las heridas en su libro El Tesoro de la verdadera cirugía y vía particular contra la común. Este método tuvo gran difusión entre los cirujanos de toda Europa y se extendió hasta América.

(c) Ibídem, p. 171. Valdez era un médico prestigioso del Hospital de las Cinco Llagas de Sevilla.

Fuentes: ADPS, leg. 108. Libros de recibo y gastos, 1576-1587; leg. 109. Libros de recibo y gastos, 1582-1589; leg. 110. Libros de recibo y gastos, 1591-1595; leg. 111. Libros de recibo y gastos, 1596-1602.

Entre todos los médicos que trabajaron en el siglo XVII en el Hospital de la Sangre destaca Francisco Jiménez de Guillén, que había sido yerno del físico Hidalgo de Agüero, a quien dedicó un epitafio y recopiló la obra del insigne cirujano para publicarla en $1604^{34}$. También, escribió y publicó algunas obras. Otro de los médicos que trabajó en este hospital y destacó fue Francisco Giménez Carmona que escribió un tratado sobre el agua y la nieve, publicado en $1616^{35}$. El doctor Francisco de Silva Olivera escribió Discurso de la providencia

34 J. Pascual Barea, "El epitafio latino dedicado al cirujano Bartolomé Hidalgo de Agüero por el médico Francisco Jiménez Guillén, Homenaje al profesor José María Estellés", Anejos de Quaderns de Filologia, 69 (2009), pp. 455-470.

35 F. Beltrán Cortés, Apuntes para una historia del frío en España, Madrid, Consejo Superior de Investigaciones 
y curación de las secas y carbunclos con contagio ${ }^{36}$. Asimismo, el médico Juan de Vega, que vivió y murió en Sevilla, dejó el cargo de médico en el Hospital de la Sangre para ir con el virrey del Perú, conde de Chinchón, a las Indias, como su médico de cámara ${ }^{37}$. Al poco tiempo de llegar al Perú fue incorporado a la Universidad San Marcos como catedrático y se convirtió en protomédico del reino. Al regresar a la Península difundió las bondades de la quina ${ }^{38}$. Incluso entre los médicos del Hospital de la Sangre de Sevilla estaba un precursor de la línea renovadora de la ciencia, los novatores, se trata del médico Miguel Melero ${ }^{39}$.

\footnotetext{
Científicas, 1983, p.197.
}

36 J. de Villalba, Epidemiologia española o historia cronológica de las pestes, contagios, epidemias y epizootias que han acaecido en España desde la venida de los cartagineses hasta el año 1801, Madrid, Imprenta de D. Fermín Villalpando, 1803, p. 12.

37 E. Torres Arancivia, Corte de virreyes: el entorno del poder en el Perú en el siglo XVII, Lima, Fondo Editorial Pontificia Universidad Católica del Perú, 2006, pp. 156-157. El médico de la Vega había llegado en el numeroso séquito del virrey en calidad de médico de cámara.

38 M. M. Boix y Moliner, Hippocrates aclarado y sistema de Galeno impugnado, por estar fundado sobre dos aphorismos de Hippocrates no bien entendidos, que son el tercero, y veinte y dos del primer libro, Madrid, Imprenta de Blàs de Villanueva, 1716.

39 J. Pardo Tomás y A. Martínez Vidal, "Las consultas y juntas de médicos como escenarios de controversia científica y práctica médica en la época de los novatores (1687-1725)", DYNAMIS, Acta Hispánica ad Medicinae Scientiarumque Historiam Illustrandam, 22 (2002), pp. 303-325; http://lagarrapataandaluza. blogspot.com/2013/11/es-historia-el-milagro-cientifico-de.html. En el año 1697, un grupo de siete médicos renovadores comenzaron a reunirse en una tertulia en Sevilla: Juan Muñoz y Peralta, Miguel Melero Ximénez, Leonardo Salvador de Flores, Juan Ordóñez de la Barrera, Miguel de Boix, Gabriel Delgado y el farmacéutico Alonso de los Reyes. Con el tiempo sería conocida como la "Veneranda Tertulia Hispalense médico-química, anatómica y matemática". 
Tabla 3. Relación de médicos que trabajaron en el Hospital de la Sangre en el siglo XVII.

\begin{tabular}{|c|c|}
\hline $1605-1610$ & $\begin{array}{l}\text { Médico Francisco Jiménez de Guillén entró a trabajar en el hospital y } \\
\text { ganaba } 37.500 \text { maravedíes, además de fanegas de trigo y cebada. El } \\
\text { cirujano se mantenía en } 20.000 \text { maravedíes. Este médico empezó a } \\
\text { trabajar también en el Hospital del Cardenal en } 1610 \text { y dejó el Hospital } \\
\text { de la Sangre. En el Cardenal trabajó hasta } 1626 \text {. }\end{array}$ \\
\hline $1611-1625$ & $\begin{array}{l}\text { Médico Bartolomé de Armellones y Monroy recibía } 37.000 \text { maravedíes } \\
\text { anuales. Este médico compartió su trabajo al enfermarse con el doctor } \\
\text { Francisco de Silva Olivera, por dos meses, marzo y abril de } 1620 \text {, con } \\
\text { el doctor Melchor de la Plaza de } 1622 \text { a } 1624 \text { y con el doctor Jiménez } \\
\text { Carmona en } 1625 \text { cuando falleció Armellones. }\end{array}$ \\
\hline $1626-1627$ & $\begin{array}{l}\text { Médico Francisco Jiménez Carmona murió ejerciendo la profesión y se } \\
\text { entregó a su viuda el salario que se le debía. }\end{array}$ \\
\hline 1628 & El médico Juan de la Vega trabajó el primer tercio de ese año. \\
\hline $1629-1636$ & $\begin{array}{l}\text { Médico Juan Bautista Montes de Oca recibía } 59.840 \text { maravedíes o } 160 \\
\text { ducados o } 2.000 \text { reales anuales. }\end{array}$ \\
\hline $1645-1646$ & $\begin{array}{l}\text { Médico Juan de Aranda murió el } 6 \text { de octubre de } 1646 \text {. El administrador } \\
\text { del hospital, Gabriel de Aranda, recibió } 53.320 \text { maravedíes del salario del } \\
\text { médico porque era su albacea y heredero. }\end{array}$ \\
\hline 1647 & Médico Francisco de Cuadros. \\
\hline 1649-1655 & $\begin{array}{l}\text { Médico Laureano de Ribera ganaba } 74.800 \text { maravedíes, igual ganaba el } \\
\text { cirujano del hospital y el barbero recibía } 18.700 \text { maravedíes. }\end{array}$ \\
\hline $1656-1664$ & Médico Juan de Salinas. \\
\hline 1665 & Médicos Andrés González Gordillo y Francisco de Aldo Moreno. \\
\hline 1667 & $\begin{array}{l}\text { Médico Francisco de Alda Moreno, le sucedió Andrés Gordillo, Francisco } \\
\text { de Torres y Francisco de Prada. }\end{array}$ \\
\hline $1668-1677$ & Médico Miguel Antonio de Ayssa. \\
\hline 1678 & No hubo médico \\
\hline 1679 & Médico Mateo de Aranda. Regresó ese año Miguel Antonio de Ayssa. \\
\hline 1681 & Médico Miguel Antonio de Ayssa. \\
\hline $1682-1695$ & $\begin{array}{l}\text { Médico Mateo de Aranda recibía } 74.800 \text { maravedíes o } 2.200 \text { reales de } \\
\text { vellón. También recibía de la convalecencia, pero fue despedido y dejó } \\
\text { de asistir. }\end{array}$ \\
\hline $\begin{array}{l}06 / 05 / 1695 \\
a \\
30 / 06 / 1697\end{array}$ & $\begin{array}{l}\text { Médico Miguel Melero fue familiar del Santo Oficio, médico de cámara } \\
\text { de su majestad y del arzobispo de Sevilla. Los patronos del hospital } \\
\text { mandaron que viviera en el hospital. Le pagaban } 160 \text { ducados o } 1.760 \\
\text { reales de vellón, además de cuatro fanegas de cebada, veinticuatro } \\
\text { arrobas de vino, doce arrobas de aceite, paja para su mula y caballo, una } \\
\text { libra de carnero diario y una libra de vaca o puerco. También, los días de } \\
\text { vigilia recibía una libra de pescado fresco y otra de salado, seis libras de } \\
\text { pan diario, tres de blanco y la otra de bagazo. }\end{array}$ \\
\hline $\begin{array}{c}01 / 07 / 1697 \\
a \\
07 / 08 / 1699\end{array}$ & $\begin{array}{l}\text { Pedro de Rayo recibió } 200 \text { reales por mes, también trabajó en el Hospital } \\
\text { del Cardenal. Falleció y se pagó a su viuda, doña Leonor Francisca } \\
\text { Moreno y Morales lo que se le debía en } 1699 \text { y } 1700 .\end{array}$ \\
\hline
\end{tabular}

Fuentes: ADPS, Libros de recibo y gastos, años 1596 a 1703, legs. 111 a 126 
En el siglo XVIII encontramos que casi todos los médicos que trabajaban en Sevilla, pertenecían a la Regia Sociedad de Medicina de Sevilla y escribían sus estudios médicos bajo la tutela de la mencionada institución ${ }^{40}$. Los temas eran diversos. Entre todos los médicos que trabajaron en el Hospital de la Sangre en ese siglo en que la medicina dejó de ser empírica y se hizo experimental estuvieron: Francisco González de León, Bonificio Ximenez de Lorite y Antonio de Santaella González.

Tabla 4. Relación de médicos que trabajaron en el Hospital de la Sangre en el siglo XVIII.

\begin{tabular}{|c|c|}
\hline $\begin{array}{c}15 / 08 / 1699 \text { a } \\
07 / 05 / 1734\end{array}$ & $\begin{array}{l}\text { Juan Francisco Pablo García ganaba } 2.200 \text { reales de vellón y cuando se jubiló recibió un } \\
\text { estipendio anual de } 80 \text { ducados. Ejerció treinta y cuatro años y diez meses y medio en } \\
\text { el hospital. Los patronos le jubilaron el } 7 \text { de mayo de } 1734 \text { y después se hizo socio de la } \\
\text { Regia Sociedad de Sevilla y participó en la elaboración de su reglamento, siendo uno de } \\
\text { los quince socios que lo firmaron el } 16 \text { de julio de } 1736^{a} \text {. Acto seguido pidió dinero para } \\
\text { su vejez y la Sociedad le entregó } 40 \text { pesos. Falleció el } 24 \text { de julio de } 1737 \text {. }\end{array}$ \\
\hline $\begin{array}{l}01 / 07 / 1734 \\
30 / 09 / 1736\end{array}$ & $\begin{array}{l}\text { Andrés de Chozas fue nombrado médico titular el } 7 \text { de mayo de } 1734 \text { y recibía } 120 \\
\text { ducados anuales o } 1320 \text { reales de vellón, es decir } 44.880 \text { maravedíes anuales. No } \\
\text { recibía su salario completo porque se extraían } 80 \text { ducados para pagar al médico jubilado } \\
\text { anterior. Renunció a su cargo por enfermedad. }\end{array}$ \\
\hline $\begin{array}{l}1736 \\
1738\end{array}$ & $\begin{array}{l}\text { José Jerónimo de Aguirre y Canzino, médico suplente, recibió salario de } 2.200 \text { reales y } \\
\text { ayuda de costa de } 400 \text { reales de vellón. }\end{array}$ \\
\hline $\begin{array}{l}01 / 12 / 1738 \\
07 / 09 / 1739\end{array}$ & $\begin{array}{l}\text { Francisco González de León recibió } 200 \text { ducados anuales, pero dejó la plaza de médico. } \\
\text { Después de trabajar en el Hospital de la Sangre fue escogido con otros médicos por la } \\
\text { Junta de Sanidad en } 1743 \text { para ir a Ceuta a realizar visitas a los hospitales y casas, con } \\
\text { el objetivo de reconocer algunos cadáveres y determinar la naturaleza de la epidemia. } \\
\text { Escribió una disertación sobre La dulcificación del agua de marina, publicada en } 1737 \text {, } \\
\text { De los morbos del útero, impreso el } 20 \text { de febrero de } 1740 \text {, Sobre el limitado poder de los } \\
\text { abortivos y La electrización para curar la perlesía, en } 1754^{b} \text {. }\end{array}$ \\
\hline $\begin{array}{l}08 / 09 / 1739 \\
26 / 11 / 1765\end{array}$ & $\begin{array}{l}\text { Juan Narváez recibió } 74.800 \text { maravedíes anuales o } 2.200 \text { reales de vellón. También, fue } \\
\text { médico del Hospital de San Lázaro de Sevilla. Murió en ejercicio. Se pagó a su viuda y } \\
\text { albacea, doña Josepha de Peraza, lo que se le debía. }\end{array}$ \\
\hline $\begin{array}{l}29 / 11 / 1766 \\
25 / 08 / 1785\end{array}$ & $\begin{array}{l}\text { Bonificio Ximenez de Lorite fue profesor de Medicina y pertenecía a la Real Academia } \\
\text { de Buenas Letras y a la Sociedad Patriótica, siendo uno de sus cuarenta fundadores y } \\
\text { socio de número y secretario primero de la Sociedad de Medicina y demás Ciencias de } \\
\text { Sevilla. Escribió Instrucción médico-legal para servir a los Reales Hospitales de San } \\
\text { Lázaro en } 1765 \text { y un artículo intitulado Sobre la lepra que surgió de su participación en la } \\
\text { inspección ocular en Lebrija en } 1764 \text {. Escribió también De las utilidades que la Química } \\
\text { puede comunicar, Del método con que Hipócrates administró la leche y si es adaptable a } \\
\text { nuestro tiempo }{ }^{c}, \text { Patología de las enfermedades de los encarcelados y De la punción de } \\
\text { la vejiga de la orina }{ }^{\mathrm{e}} \text {, Sobre los baños y Del uso del álcali volátil en los males nerviosos". }\end{array}$ \\
\hline $\begin{array}{c}01 / 09 / 1785 \\
1809\end{array}$ & $\begin{array}{l}\text { Antonio de Santaella González fue uno de los más ilustres médicos sevillanos del siglo } \\
\text { XVIII y fue socio de número de la Regia Sociedad de Medicina de Sevilla. Se graduó } \\
\text { de bachiller en Medicina en la Universidad de Sevilla en } 1766 \text {. Médico del Hospital de } \\
\text { la Sangre desde } 1785 \text {. En } 1792 \text { obtuvo la licenciatura y grado de doctor y dictó una } \\
\text { cátedra de Clínica en la universidad hasta } 1824 \text {. También fue un escritor prolijo sobre } \\
\text { Medicina, dieta y Ciencias Naturales. Denunció en sus escritos la suciedad de la ciudad } \\
\text { y de los estercoleros en la puerta de la Macarena y recomendó alejar los cementerios } \\
\text { de las ciudades }{ }^{g} \text {, así como rociar agua y vinagre en las zonas contaminadas. Escribió } \\
\text { varios artículos. Uno de ellos trato sobre el estudio de la constitución de cada individuo } \\
\text { para conocer el influjo en la evolución de la enfermedad, realizó comentarios a los libros } \\
\text { dietéticos de Hipócrates, estudió sobre fiebres intermitentes y otros temash }\end{array}$ \\
\hline
\end{tabular}

(a) Ibídem, p. 17.

(b) Memorias literarias de la Real Academia Sevillana de Buenas Letras. Sevilla, Real Academia Sevillana de Bue-

40 A. Hermosilla Molina, Cien años de medicina sevillana (La Regia Sociedad de Medicina y demás Ciencias de Sevilla, en el siglo XVIII), Sevilla, Ayuntamiento de Sevilla, 2001, p. 601. La ciudad de Sevilla tenía en la segunda mitad del siglo XVIII cincuenta y seis médicos, doscientos barberos-cirujanos y treinta boticarios. 
nas Letras, tomo I, p. LXXXII; F. Aguilar Piñal. Bibliografía de autores españoles del siglo XVIII, Madrid, CSIC, 1999, tomo IX, p. 311; A. Hermosilla Molina, Cien años de medicina sevillana..., pp. 217-661. Francisco González de León fue médico de cámara del rey, socio de número, secretario perpetuo y vicepresidente de la Real Sociedad de Sevilla, académico, secretario del círculo hispalense de la Real de Oporto en Portugal y socio la Sociedad Médico-Quirúrgica de la Real Congregación de Nuestra Señora de la Esperanza de Madrid. Académico sevillano en la de Buenas Letras y de la Real de Medicina, que lo elevó a vicepresidente, siendo después su secretario general perpetuo. Gran publicista. La Real Academia Quirúrgico-Portuense de Oporto tenía ramificaciones en todas las provincias españolas.

(c) F. Buendía y Ponce, Memorias académicas de la Real Sociedad de Medicina y demás Ciencias de Sevilla. Extracto de las obras y observaciones presentadas por Buendía y Ponce, presbítero y medico de cámara de su majestad, titular del Santo Oficio, Sevilla, Vásquez Hidalgo y compañía, 1785, pp. 393-408 y 428-444.

(d) B. J. Ximénez de Lorite, "Patología de las enfermedades de los encarcelados señalando sus remedios prophylacticos y curativos", en Memorias académicas de la Real Sociedad de Medicina y demás Ciencias de Sevilla, 1786, vol. IV, p. 240.

(e) V. González, Memorias académicas de la Real Sociedad de Medicina y demás Ciencias de Sevilla. Extracto de las obras y observaciones presentadas, tomo IV, Sevilla, Josef Padrino, 1786, pp. 232-605.

(f) F. Aguilar Piñal, Bibliografía de autores españoles del siglo XVIII, tomo IX, Madrid, CSIC, 1999, pp. 345-485.

(g) A. Hermosilla Molina, Cien años de medicina sevillana..., p. 635. Santaella trabajó diariamente en el Hospital de la Sangre y denunció que la muralla en el arrabal de la Macarena era utilizada como estercolero. El campo entre el convento de capuchinos y la Macarena era un sitio donde se tiraban animales muertos y un abrevadero de manadas de puercos por las lagunas dejadas por las inundaciones.

(h) R. Reyes Cano y E. Vila Vilar, El mundo de las academias, Universidad de Sevilla, 2003. Algunos de sus artículos son "De la latitud que admite el régimen y dieta del puerperio", 26 de abril 1792; "Del influjo de las pasiones del ánimo en las enfermedades que llaman vaporosas y más adecuado método de tratarlas", 23 de abril 1795; "De los caracteres generales de las enfermedades simpáticas y sus respectivos tratamientos", 14 de enero de 1794; "Si era posible prever las epidemias y cuales sean los medios de precaverlas", 20 abril 1797; "Descripción histórica medica de las calenturas epidémicas pútridas malignas que padecieron los individuos dela casa de niñas huérfanas educandas llamada beaterio de la Santísima Trinidad en 1795, diciendo su historia y curación algunas reflexiones médico-practicas", 21 enero 1795. Este médico fue empírico y experimental, fiel seguidor de Hipócrates, a quien cita y recurre en sus trabajos.

Fuentes: ADPS, Libros de recibo y gastos, años 1697-1792, legs. 126 a 134. Libros de pago de salarios, de 1694 a 1809, legs. 187 y 188.

\section{CARACTERÍSTICAS DEL ÁREA DE LA ENFERMERÍA DEL HOSPITAL DE LAS CINCO LLAGAS}

\subsection{El acceso de las enfermas a la enfermería de san Pedro}

Desde la fundación del hospital, en 1503, un físico revisaba diariamente a las enfermas que esperaban en la entrada del hospital para determinar si podían ingresar a enfermería ${ }^{41}$. Después de auscultar a las enfermas en el recibidor, determinaba si podían ser recibidas en el hospital. Sólo podían ser recibidas las que tenían calenturas, desarreglos estomacales y otras enfermedades comunes. No se recibían a las enfermas portadoras de enfermedades contagiosas, ni las que requerían curaciones complicadas e incurables, ni héticas, tísicas, gálicas, sarnosas, tiñosas, siendo derivadas al hospital que correspondiese su curación ${ }^{42}$. Si la enfermedad era dudosa, el administrador se podía inclinar a favor de la enferma hasta que se determinaba su enfermedad. Sin embargo, se han detectado ingresos de enfermas no permitidas según constitución, portadoras de "males contagiosos", incurables, incluso esclavas cautivas, cuya entrada de tiempo en tiempo era reiteradamente prohibida como

41 ADPS, Constitución de las Cinco Llagas de 1503, leg. 1A.

42 BC, Constitución del Hospital de las Cinco Llagas de 1734, const. 9. Acuerdo del año 1675, folio 135r. 
en $1675^{43}$ y en $1678^{44}$.

Desde 1604, el médico tenía la obligación de curar a todos los criados del hospital de cualquier enfermedad que tuviesen, aunque fuese contagiosa ${ }^{45}$. En la revisión médica de ingreso al hospital era obligatorio que la madre enfermera recibiera a las nuevas enfermas junto con el médico, remarcado en la junta de $1657^{46}$.

Según el reglamento, no se recibían embarazadas para parir ${ }^{47}$, pues el hospital no realizaba partos, pero sí mujeres parturientas enfermas, asistiéndolas durante el parto y haciéndose cargo de los niños nacidos, remitiéndolos a la casa de expósitos o Casa Cuna, con certificación del sacerdote del hospital. Y en caso que no se le admitiese, se le buscaba ama o nodriza, "para que lo críe a costa de este hospital, durante el tiempo que la madre pertenecía enferma, y no teniendo sus padres caudal para ello". Y lo mismo se ejecutaba con las criaturas que traían sus madres al pecho y venían enfermas a curarse. Al menos en el siglo XVII, la presencia de la comadrona era prácticamente mensual. La comadrona y la nodriza no eran incluidas como trabajadoras en los padrones, por la prohibición de acceso a enfermas embarazadas, las ingresaban en gastos extraordinarias en los libros de recibo y gasto del hospital ${ }^{48}$.

Otra vez, se prohibió fehacientemente recibir mujeres a punto de parir en el hospital en 1727. Se podían recibir mujeres embarazadas que habían sufrido algún accidente y si parían se las ubicaba en un sitio separado de las enfermas y doncellas de dote ${ }^{49}$. Así, el propio hospital trasgredía sus propias normas al tener que admitir embrazadas y matronas, a pesar de la reiterada prohibición normativa ante esta contundente realidad femenina.

Tampoco, el Hospital de las Cinco Llagas recibía a mujeres cautivas, pues sus amos estaban obligados a curarlas a su costa. Si por alguna razón era preciso recibir alguna, se hacía obligando al amo a pagar cuatro reales de alimentos al hospital por cada día que se mantuviese en él. Sin embargo, si se justificaba que el amo era pobre, y no tenía caudal para ello, se recibía a la esclava, como a las demás enfermas. Los amos solían recurrir a una estratagema para facilitar la entrada de sus esclavas al hospital a través de la carta de libertad, y como solía ser falsa, se obligaba que las mencionadas cartas tuviesen una antigüedad de seis meses al momento del ingreso al hospital.

Antes de ingresar a enfermería, las enfermas eran despojadas de sus ropas, las que se escribían en un libro para determinar los bienes que traían y el día que los ingresaban,

43 ADPS, Libro de juntas o actas capitulares (1659-1687), leg. 4B, folio 135r (1675): "[...] atento a que tienen noticia que se reciben en este hospital algunas enfermas de males contagiosos y otras incurables y que asimismo se traen a curar al dicho hospital algunas esclavas cautivas de aquí adelante no se reciba ninguna de las tres especies, (sin licencia especial de los patronos reverendos [tachado]) sobre que encargan la conciencia al Sr. administrador y a los demás ministros para que den cuenta de lo que se hiciere y quien ocasionó la dicha entrada y recibo".

44 ADPS, Ibídem, folio 150r (1678): "[...] se tiene noticia que por diferentes favores se suelen recibir para curación en este hospital algunas esclavas con diferentes pretextos, acordaron y mandaron que el Sr. Administrador no reciba a ninguna esclava para curación y que la que está en el hospital se la venda cuando antes [...]".

45 ADPS, Autos capitulares (1584-1635), leg. 4A, folio 49r (1604).

46 ADPS, Libro de juntas o actas capitulares de patronos del Hospital de las Cinco Llagas (1637-1658), leg. 4B, folio 227r (1657).

47 ADPS, Libro de autos capitulares (1734-1763), leg. 4B, folio 108v (1751).

48 P. E. Rivasplata Varillas, Aproximación histórica de la enfermería femenina en Europa y América: la enfermería en el Hospital de las Cinco Llagas de Sevilla y los hospitales de Lima en el XVIII y parte del XIX, Berlín, Editorial Académica Española, 2012.

49 ADPS, Libro de autos capitulares (1716-1734), leg. 4B, folio 83r (1727). 
que una vez limpios se guardaban. Las enfermas recibidas eran conducidas y acompañadas por la enfermera mayor a las enfermerías donde se les vestía con una prenda de lienzo. Era necesario que las enfermas se confesasen y comulgasen a continuación de ser admitidas, es decir, el día que entraban al hospital, o, lo más pronto posible. A las enfermas se les podía recibir a cualquier hora, aún fuera del horario estipulado para ello, es decir, dos horas en la mañana y otras dos en la tarde ${ }^{50}$. La confesión al entrar en el hospital era una exigencia eclesiástica y médica, pues se consideraba que las enfermas debían suplicar a la divinidad que apartara "su ira y castigo" de ellas para poder ser atendidas ${ }^{51}$. La enferma que ingresaba estando grave, entonces, se le daba la comunión y se le instaba hacer testamento. Una vez concluido los deberes espirituales, se procedía a la curación del cuerpo, dejando a la enferma al consejo del médico o cirujano.

\subsection{El trabajo realizado por las enfermeras en la sala de san Pablo}

El trabajo desempeñado por estas mujeres era continuo, inclusive dormían con las enfermas, turnándose para estar al tanto de sus necesidades. Al amanecer, las enfermeras limpiaban la sala y luego atendían a las enfermas que amanecían purgadas, sacando el orinal debajo de sus camas. Algunas purgaban en la mañana y se les acudía con el abrigo necesario.

Después de la limpieza, un sacerdote y un sacristán ingresaban a la sala de san Pablo para realizar la misa matutina, a las seis en verano y a las siete en invierno. Las misas se hacían en el altar de la enfermería antes de la visita médica y la curación de las enfermas ${ }^{52}$. Una vez terminada, la enfermera mayor les suministraba las medicinas que el boticario le había entregado el día anterior. Los jarabes, píldoras, laxantes y otras bebidas, que tenían que tomar antes que llegara el médico, estaban separados en vasos numerados que correspondían a los de cada cama. Las enfermas, vestidas en lienzo, tenían cerca de sus camas algunas ropas de paño para cubrirse cuando querían sentarse en las camas o levantarse a hacer sus necesidades.

Cuando el médico entraba a visitar a las enfermas que yacían en sus camas, un portero avisaba al administrador quien daba la orden de tocar la campana, que estaba sobre la puerta de la enfermería de san Pedro, para que acudieran a la visita el cura semanero, el boticario, el sangrador, la enfermera mayor y las jóvenes aprendices en enfermería que estuviesen en el cuarto ${ }^{53}$. También podía unirse a este grupo los máximos responsables del área femenina y del hospital, es decir, la madre mayor y el administrador. Empezaba la visita interrogando a las enfermas sobre sus padecimientos, una vez observada y pulsada

50 ADPS, Libro de autos capitulares (1764-1787), leg. 4B, folio 3r (1764): "Que en recibir a las pobres enfermas no se observe hora fija, de modo, que a cualquiera hora, que venga encuentren el recurso pronto, aún fuera de las dos horas de mañana y tarde en que comúnmente se reciban".

51 L. Granjel, La medicina española del siglo XVII, Salamanca, Ediciones Universidad de Salamanca, 1978, p. 62.

52 ADPS, Ibídem, folio 137r (1784). Sin embargo, había épocas especiales en las cuales se hacían más misas de lo normal con sermones en las enfermerías en tiempo de cuaresma por las mañanas y las tardes, entonces se pagaba al cura encargado de ello sesenta reales de vellón por la misa.

53 ADPS, Libro de juntas o actas capitulares (1659-1687), leg. 4B, folio 65r (1665). En 1665 se designaron dos médicos, atendiendo alternativamente cada uno un mes y sustituyendo al que quedase enfermo. Se creó una nueva plaza pero sin gasto al hospital pues se dividió el sueldo de un médico en dos; Libro de autos capitulares (1734-1763), leg. 4B. folio 75r (1747). Los médicos visitaban a las enfermas y heridas, a veces a las incurables, pero nunca a las agonizantes. Si los facultativos lo ordenaban, se administraba el uso de leche de burras y baño para la curación de las enfermas del hospital, pero nunca para convalecer. 
la paciente, el médico dictaba las medicinas al boticario que tomaba razón, orientándose por los números de las camas. No se personalizaba a la enferma, siendo identificada por su número de cama ${ }^{54}$. El sangrador, por el mismo orden, en otra libreta, apuntaba las sangrías y si no estaba, las anotaba el boticario, entregando las indicaciones cuando viniese ${ }^{55}$. Las enfermeras ponían gran cuidado en lo que dispusiera el médico, tocante a las unciones y otras medicinas, e incluso este enseñaba a aquellas el modo correcto de aplicarlas, las horas de darlas. Y lo mismo en lo que se refiere a las comidas (que se consideraban tan importantes como las medicinas), cuyas indicaciones las anotaba el cura semanero, para ejecutarlas con acierto.

Al terminar la visita médica, la enfermera y sus ayudantes llevaban a cabo lo dispuesto por el médico: lavativas, purgas, medicamentos y unciones. El sangrador realizaba las sangrías y ventosas, así como el boticario, las medicinas y los curas administraban los sacramentos a las enfermas que el médico había desahuciado.

La comida era determinada por el médico y se servía temprano, en verano de diez a once y en invierno de once a doce, ante la presencia del administrador, cura semanero, madre enfermera y criadas. Una vez que el cura bendecía la comida, procedía a repartirla. Las criadas se encargaban de llevarla a cada enferma, siguiendo las indicaciones de la madre enfermera que seguía las dadas por el médico.

La sala de san Pedro se cerraba después de la comida para que las enfermas durmiesen la siesta mientras las enfermeras cumplían con las prescripciones médicas y estuviese todo listo para la segunda visita médica de la tarde. Las enfermeras tenían obligación de avisar al médico los nuevos accidentes que observaban en el transcurso del día en cuanto a la evolución de las enfermas entre una y otra visita. Cada vez más se daba importancia al binomio médico-enfermera, pues en 1750, el hospital determinó que en la visita del médico a enfermerías sólo se acercasen a las enfermas a oír su relación el médico, la enfermera y el boticario, este algo distante, para que escribiese las anotaciones ${ }^{56}$.

El lapso de tiempo entre la visita y la cena era utilizado para que las enfermeras y boticarios cumpliesen lo indicado por el médico. El cura semanero administraba los santos sacramentos, confesiones y extremaunciones. Antes que se diese principio a la cena, se tocaba la campana para que acudieran el administrador y los curas que debían hallarse presentes en la enfermería de san Pedro. La cena empezaba con la bendición de la comida y luego el cura semanero y la madre enfermera la repartían ante la presencia del administrador. Uno de los curas se acercaba a cada enferma para inquirir lo que apetecía. Acabada la cena, un cura hacía señal con la campana al tiempo que los ministros varones salían de las enfermerías. La cena duraba una hora, de siete a ocho, después de lo cual se cerraba la sala de san Pedro.

En 1578, se dio la orden de que a las enfermas que salían del hospital se les diese medicinas, un real o dos, ropa de las difuntas y se les trasportase a sus casas en "sillas de caridad". Además con parte del dinero obtenido de las ropas vendidas en almonedas, el

54 ADPS, Libro de autos capitulares (1734-1763), leg. 4B, folios 67v y 68r (1745). "Que porque se han quejado algunas enfermas, que el médico en las visitas, no da espera a oír el informe que quieren hacerle de los accidentes que padecen por ejecutarlo con mucha prisa, mandaron los Srs. patronos se le haga saber al médico, oiga dichos informes con toda claridad, y que no se aparte de la cama de una enferma, para visitar otra, hasta que el botiller y boticario, hayan apuntado las medicinas, que ordenare a cada una enferma".

55 ADPS, Constitución del Hospital de las Cinco Llagas de 1624, folio 6v. Antes de 1734, el barbero era el que anotaba las disposiciones del médico en una tabla: "El barbero llevaba una tabla de barniz en que escribía las sangrías y ventosas y las comidas que se han de dar a las enfermas y a qué hora y las dietas".

56 ADPS, Libro de autos capitulares (1734-1763), leg. 4B, folio 95v (1750). 
hospital adquiría bulas de cruzadas para la absolución de los pecados, que se ponían sobre el cuerpo de las difuntas al ser enterradas. En aquel entonces, el hospital no aceptaba herencias de las enfermas pobres por la poca utilidad de las mismas, salvo excepciones ${ }^{57}$. El dinero que se daba a las convalecientes fue una práctica que se truncó temporalmente, pues en 1582, se ordenó que toda la ropa vendida se destinara a misas por las almas de las difuntas ${ }^{58}$. Pronto se recuperaría esta tradición.

\subsection{Las doncellas de dote o aprendices de enfermería del Hospital de la Sangre}

Estas jóvenes trabajaban por un salario, comida diaria y una dote si habían trabajado tres años consecutivos en el hospital ${ }^{59}$. Las llamadas doncellas de dote surgieron en 1587 por diversos motivos. Uno de los cuales sería una respuesta que este hospital, que estaba bajo dirección de la Iglesia, daba al fomento de matrimonios públicos que impuso el Concilio de Trento. Otro motivo sería no prescindir de muchachas conocedoras de su trabajo después de años de experiencia. El hospital exigía a las muchachas que quisieran trabajar como doncellas de dote la entrega de certificados de bautismo. Una vez casadas se les entregaba la dote para lo cual debían entregar su fe matrimonial expedida por el cura y un documento notarial en el que el esposo aceptaba haber recibido la dote del hospital.

Las doncellas de dote de enfermería estaban bajo la dirección de la madre enfermera y se dedicaban al cuidado y asistencia de las enfermas con calenturas, convulsiones, problemas estomacales y cualquier enfermedad que no fuesen las prohibidas por el hospital, es decir, héticas, tísicas, gálicas, sarnosas, tiñosas, bubosas, leprosas ni que tuviesen enfermedades contagiosas. Tampoco atendían a embarazadas a punto de parir. Estas jóvenes trabajaban en la sala de enfermería denominada de san Pedro. Esta área era una de las que tenía mayor número de doncellas de dote, cinco, debido a que muchas de las quinientas a dos mil doscientas enfermas anuales que recibía este hospital eran derivadas al área de enfermería.

Las doncellas se encargaban de realizar todo lo indicado por la madre enfermera y tenían la obligación de asistir a las dos visitas médicas diarias porque el médico enseñaba el modo de ejecutar las unciones, lavativas, purgas y dar las medicinas a las enfermas y también a qué horas debían hacerlo. Se trataba de clases prácticas. Una de las funciones fundamentales de estas jóvenes era observar y vigilar a las enfermas, pues tenían obligación de avisar a su jefa, la madre enfermera, y esta al médico, los acontecimientos que observaban en el transcurso del día y noche en cuanto a la evolución y padecimiento de las enfermas de una a otra visita. Asimismo, avisar si alguna enferma estaba moribunda para que el cura semanero le diera la extremaunción.

Durante el almuerzo y cena, las doncellas ayudaban en la distribución de la comida que repartía el cura, en escudillas y cubiertos de estaño, siendo llevada a cada enferma por las doncellas bajo la dirección de la madre enfermera. Esta labor exigía esfuerzo por el calor que desprendían los anafes sobre los que era transportada la comida desde la cocina, en cazuelas grandes de cobre. Las doncellas comían en la enfermería en un bufete

57 ADPS, Libro de autos capitulares (1556-1584), leg. 1B, folio 73r (1578).

58 ADPS, Ibídem, folio 81r (1582).

59 P. E. Rivasplata Varillas, Las doncellas de dote del Hospital de las Cinco Llagas de Sevilla. Una lectura en clave de género, Berlín, Editorial Académica Española, 2011, pp. 1-345. La dote que recibían de cincuenta ducados. La cantidad análoga a la que recibían las jóvenes pobres de instituciones de caridad como la Casa de la Misericordia de Sevilla en el Antiguo Régimen. 
pequeño después de atender a las enfermas. Otra de sus labores era controlar que no comieran comida prohibida por los médicos, durante las visitas familiares ${ }^{60}$.

La disciplina en la enfermería fue incrementándose, pues hubo una época en el siglo $\mathrm{XVI}$ en que los patronos se quejaban que en el área femenina algunas jóvenes usaran zapatos dorados y lazos, a pesar de la férrea disciplina llevada a cabo por las madres. En el XVII, la disciplina tornó a ser más rígida aún y se tendió a la beatería. Así, las jóvenes que trabajaban en la enfermería estuvieron obligadas a llevar toca de lino o de beatilla desde 1587 hasta 1698, pero por el calor de Sevilla, el sudor y el continuo contacto con las enfermas, hacían que se ensuciaran mucho y solían ser causa de enfermedades, por lo que se restringió su uso en verano, durante el calor, en época de exceso en trabajo y durante periodos de peste, con la condición que tuviesen el cuello y los hombros tapados ${ }^{61}$. También, las enfermas llevaban la toca en ocasiones especiales como durante las visitas eclesiásticas. La toca fue proporcionada por el hospital.

A pesar de la tácita prohibición de admitir a enfermas parturientas, este hospital de mujeres no pudo evitar atender partos de las mujeres embarazadas recibidas que habían sufrido algún accidente o estaban enfermas. Si parían se las ubicaba en un sitio separado de las enfermeras doncellas, se las aislaba. De esta manera, se trató de evitar que las doncellas de dote presenciaran el acto de parir, porque se alegaba iba contra su decoro por "las indecencias que ocasiona tal función a las doncellas sirvientas"62. Varios sentimientos encontrados se han barajado en torno a los partos: rechazo, respeto y miedo. La comadrona que iba al Hospital de las Cinco Llagas no debía enseñar su oficio a las jóvenes que trabajaban en el hospital, ya que el estatuto prohibía el ingreso de enfermas embarazadas, por lo que se supone que no deberían de aprender este oficio. Pero era prácticamente imposible evitar la presencia de la comadrona, a pesar que el hospital trataba de salvaguardar la pureza mental o decoro de estas jóvenes.

Estas jóvenes eran consideradas enfermeras y el número que trabajó en el área de san Pedro se desconoce con precisión. En los libros salarios no se hacen distinciones entre las doncellas de dote que trabajaron en las diferentes áreas del hospital desde finales del siglo XVI. También figuran en los testamentos de enfermas al participar como testigos, como fue el caso de la criada Estebania de Salas realizada en 1606, en la que indica textualmente:

60 ADPS, Libro de autos capitulares (1764-1787), leg. 4C. folio 30v (1769). Las visitas de los parientes a las enfermas se hacían hasta 1769 en forma diaria, posteriormente se restringió a sólo dos días a la semana: domingos y jueves por la tarde después de la visita del médico. Sin embargo, el administrador podía dar licencia particular de entrada cualquier otro día; Libro de autos capitulares (1764-1787), leg. 4C, folio 153r (1787). En 1787 se prohibió la visita de parientes incluso los días asignados, entrando sólo con expresa licencia del administrador; Libro de juntas y acuerdos capitulares (1800-1835), leg. 4C, folio 44v (1805). Desde 1805, se permitió la visita de parientes a enfermería los jueves por la tarde.

61 ADPS, Libro de juntas capitulares (1687-1715), leg. 4B, folios 78v y 79r (1698). Las madres y doncellas traían todo el año de invierno y verano, cubiertas las cabezas con tocas de lino o de beatilla, sin embargo, se habían experimentado graves enfermedades en ellas, especialmente en verano y de los muchos calores, y en tiempo de mucho trabajo por el mucho concurso de enfermedades. "Los patronos mandaron en 1698 que se les permita a las madres y doncellas en tiempo de verano y de demasiados calores y de mucho trabajo y concurso de enfermedades no usen las tocas puestas en las cabezas sino que las traigan del cuello abajo, tapados los hombros de manera que estén y anden con la mayor honestidad y decencia posible".

62 ADPS, Autos capitulares de este Hospital de la Sangre (1716-1734), leg. 4B, folio 83r (1727); M. E. Perry, "Las mujeres y su trabajo curativo en Sevilla, los siglos XVI y XVII", en M. Matilla y M. Ortega (eds.), El trabajo de las mujeres: siglos XVI-XX, Madrid, Universidad Autónoma de Madrid, 1996, p. 65. En una época en que se creía que las parteras promovían la inmoralidad. El pecado de las parteras eran sus conocimientos, los cuales ayudaban a las mujeres que querían tener poder sobre su cuerpo y su sexualidad al saber practicas contraceptivas y abortivas. 
"[...] se recibió juramento de Francisca María, doncella, hija de Francisco de Herrera vecino de Sevilla, enfermera en el dicho hospital [...]"63.

\section{EVOLUCIÓN Y DESCRIPCIÓN DE LA SALA DE ENFERMERÍA LLAMADA SAN PEDRO}

El primer establecimiento del hospital era pequeño y estaba en la parroquia de santa Catalina, intramuros de la ciudad. La limpieza era fundamental en este hospital desde su fundación por eso en su primer reglamento, de 1503, se dispuso que en cada sala hubiese tinajas colgadas, llenas de agua, para que las enfermas se limpiaran las manos y que el agua se cambiara las veces que fuese necesario ${ }^{64}$. Pronto, las quince camas de la fundación se duplicaron en 1520. La sala de enfermería tenía armarios y despensas donde se guardaban manteles y pañuelos para la mesa, así como almillas, mantillas y camisas de lienzo que se entregaban a las enfermas para cubrirse. En 1541, la enfermería tenía cuarenta y ocho camas, todas con doble colchón relleno de lana, almohadas, sábanas, colchas, mantas de paño y frazadas. En medio de la habitación estaba una mesa grande de bisagras con manteles y pañuelos. Disperso había otras mesas pequeñas, tablas de madera grandes con sus bancos, poyales, estrados, sillas de espaldas y de caderas, arcas y un cofre de madera. Las paredes tenían un aparador, reposteros, un armario para los ornamentos y otro para ropaje de lino. Una cortina de lienzo pintada estaba colgada entre la enfermería y la capilla y servía para separar estas dependencias.

El nuevo edificio del Hospital de las Cinco Llagas en el arrabal de la Macarena, extramuros de la ciudad se usó desde 1559. Este establecimiento era más amplio y tenía una enfermería llamada san Pedro. El área de la enfermería tenía dos plantas ${ }^{65}$. La enfermería de la planta baja se usaba en verano y la planta alta en invierno, pues en Sevilla, la costumbre de vivir en los bajos en verano estaba bastante arraigada en el Antiguo Régimen. Las enfermas y sus respectivas camas eran trasladadas al cambiar la estación y, poder así, superar los rigores del clima sevillano. Estas habitaciones eran limpiadas por operarios externos en junio y en octubre y estos gastos extraordinarios eran consignados en los libros de recibo y gastos.

Había dos puertas grandes de acceso a las enfermerías que fueron reducidas y protegidas con canceles para dar más abrigo a las enfermas y evitar que el calor de los anafes u hornillos de carbón se escapara. En las enfermerías, las camas estaban numeradas y cada una se componía de bancos y tablas de madera con pies de hierro con dos colchones, dos sábanas, dos almohadas, un paño blanco, frazadas y cobertores que necesitasen las enfermas. Entre una y otra cama estaba una banquilla o mesilla sobre la cual se colocaban con toda limpieza los vasos y jarrillos de las bebidas; y asimismo un servicio para los orinales con su funda de madera. Cada una de las camas tenía en lo alto de la cabecera su número de orden descubierto y fijo en la pared, para que por él se orientase el médico y cirujano durante sus visitas y, también, las enfermeras. En caso

63 ADPS, Testamento de Estebania de Salas 1606, leg. 1A, folio suelto.

64 ADPS, Constitución del Hospital de las Cinco Llagas de 1503, leg. 1A.

65 P. J. Rueda Ramírez, "Las transformaciones urbanas en la modernidad, 1500-1750", en La ciudad y su gente. Historia urbana de Sevilla, Sevilla, Escuela Libre de Historiadores, 2005, pp.101-121. En 1576 la población sevillana había crecido de forma espectacular... algunas casas se construyeron como viviendas unifamiliares con dos plantas, una para el verano y otra para el invierno, de ahí el "par de casas", un dos en una sola vivienda muy adecuado para la climatología. Y también estaban casas más modernas de una sola planta y corrales. Macarena, un núcleo urbano fuera de Sevilla, se inicia en el siglo XVI. 
de epidemia, que era bastante frecuente en Sevilla, las camas se disponían como mejor convenía a la situación de emergencia.

En el año de 1567, esta enfermería hacía uso de un crucifijo pequeño de madera para acercarlo a la enferma desahuciada y moribunda. Además mantenía la sobriedad con un aparador de madera donde se guardaban ciento veinticuatro camisas, sesenta y seis faldellines, treinta y cinco cofias, cincuenta y una mantillas de paño azul para que las enfermas cubriesen sus cabezas, así como sesenta paños, cincuenta y nueve sabanas de paño blanco para soportar el frío. También había cien jarros de estaño para agua y lo necesario para cumplir con las prescripciones médicas, como cubiletes para las purgas, cuatro jeringas de cobre, dos bacines, dieciocho bacinetas, un plato de estaño mediano con su jarro de pico para dar aguamanos a las enfermas, dos copas de cobre, un brasero mediano y un anafe de hierro. El alumbrado se efectuaba con cinco candeleros de hierro, siete candiles y un candelero pequeño de azófar. Los implementos utilizados durante las comidas eran setenta y siete platos de estaño, setenta y seis escudillas de estaño, dos platos de azófar, cántaros de cobre, dos aguamaniles de cobre, dos cuchillos, salsero de estaño, aceitera de cobre, dos calderos grandes de cobre para calentar agua. Mesas, bancos, camisas y pantuflas de dos suelas. Todo lo mencionado había sido comprado por la inauguración del nuevo hospital en el arrabal de la Macarena.

En 1603, la enfermería de san Pedro compartía su espacio con cirugía y tenía ciento diez camas. Cada una separada de la otra por una mesita de madera. La sala de san Pedro tenía instalada en una esquina un altar de madera que tenía tallado el emblema de las Cinco Llagas, con frontal, cubierto de manteles, sobre el cual descansaban vasos para agua bendita con sus hisopos. La habitación tenía dos candeleros de madera y otros dos de azófar, seis sillas de madera y un confesionario de madera. Había un cuadro grande de un crucificado junto a la Virgen y san Juan, otras imágenes pequeñas y cuatro cruces de madera que se usaban cuando morían las enfermas. Los implementos necesarios para atender a las enfermas consistían en once peroles de cobre para efectuar las sangrías, seis cazos con cremas para untar, dos jeringas, una olla de cobre, un brasero de hierro, una copa de cobre, siete candiles y un almirez de metal. Los utensilios de limpieza de la habitación consistían en tres calderetas de cobre para fregar el piso, utilizados cuando lavaban la enfermería. Un cortador de madera donde se cortaba la carne para comer y un ara donde se guardaban las escudillas y cubiertos de estaño. El inventario de 1606 indica que en enfermería había ciento tres camas con una mesita de madera entre ellas. Había un altar de madera con un frontal y un escudo de las Cinco Llagas, con manteles y cuatro candeleros de madera y azófar. Un tablón de la crucifixión, otras imágenes pequeñas y cuatro cruces de madera. Había sillas y confesionarios de madera ${ }^{66}$.

La enfermería de san Pedro llegó a compartir su sala y sus servidoras con cirugía hasta 1624 e incluso albergó a enfermas agonizantes e incurables en el periodo de 1620 a 1641. De esta manera, la enfermería solía hacerse cargo de las nuevas especialidades, cediendo su espacio y mano de obra hasta que se designaban sus propias servidoras y construyesen las nuevas salas a ocupar. Por lo explicado anteriormente, en 1613, la enfermería de san Pedro estaba conformada por tres áreas. En un lado estaban las cuarenta y cinco camas de las enfermas curables, donde estaban incluidos cuatro camas para la madre enfermera y tres criadas. En otra parte estaban las catorce camas para enfermas con cámaras. La tercera parte estaba destinada para las heridas, ubicadas en cuarenta y cinco camas en las que estaban incluidas las de sus tres servidoras.

66 ADPS, Inventario de los bienes y joyas de oro y plata y brocado, seda, paño, lienzo, cobre, hierro, madera y otras cosas que tiene este Hospital de las Cinco Llagas de esta ciudad el cual se hizo por mandado de sus paternidades los padres priores patronos de este dicho hospital en cinco de mayo de 1603, leg. 1A. 
Una parte de la sala de san Pedro se destinaba al culto divino, caracterizada por un altar desde donde se decía la misa a las enfermas ante un crucifijo grande pintado en lienzo, con frontal, manteles, ara y dos candeleros de madera. Había otro altar de madera a modo de retablo de la crucifixión con un frontal y manteles. También, un Cristo de bulto, cinco cruces de madera, una copa grande y un candelero de azófar. Frente al altar y entre las camas había una mesa y una banca que servía de cortador con su lienzo y en una de las paredes laterales estaba el aparador donde se guardaban los platos, escudillas, cubiletes, cántaros, ollas, caldereta de cobre, platos donde se lavaban las manos los médicos y cirujanos. Y en un arca se guardaba la colación y las almendradas de las enfermas. En la habitación había candeleros grandes de hierro y, también, candiles de garabato y de azófar con velas y cordeles.

En 1636, las enfermas curables seguían compartiendo habitación con las que tenían cámaras, las incurables y las agonizantes. Las heridas ya habían sido trasladadas a otra sala. Así, la sala de san Pedro tenía, en aquel entonces, cuarenta y ocho camas para enfermas curables, siete tarimas bajas para la que sufrían cámaras, veintitrés camas altas para agonizantes y veinte tarimas altas para incurables. También dormían en san Pedro la madre enfermera y sus tres ayudantes, la madre de buen morir y dos ayudantes. Cada cama era de bancos y tablas de hierro con dos colchones, dos sábanas, dos almohadas y dos cobertores uno de pelo y otro de paño ${ }^{67}$.

Nada aún estaba fijo en la habitación y se trasportaban al producirse la mudanza en el cambio de estación. El altar destacaba por tener frente a él un cuadro grande al óleo en montura dorada del crucificado con la Virgen y san Juan. La mesa del altar estaba adornada con un frontal de damasco blanco con cenefa bordada de seda, con un atril muy viejo, una campanilla, y un perol pequeño de metal para agua bendita con su hisopo de hierro. También, había un crucifijo de talla antigua, un misal muy viejo, cuatro candiles de azófar, una toalla grande para la comunión, dos pares de manteles blancos, un sobrepelliz, una estola verde de brocatel, una alacena y en ella un vaso de plata donde estaba el santo óleo, además un bufetillo con su cajón para cuando se sacramentaban las enfermas y un paño de punta que se pone encima para este efecto.

Para las curaciones había una fuente de latón y una toalla de lienzo para que se lavara y secara el médico, cinco cazos de cobre para los aceites, una jeringa, un almirez grande, un anafe de hierro, una caldera mediana, una copa de hierro, un perol de estaño y otro de cobre. Cuatro cántaros de cobre para las aguas cocidas, dos cubos de madera grandes y cuatro cubetas de madera más medianos estaban distribuidas por la habitación. Para la comida había un calderillo de cobre donde se daba el caldo a las enfermas y dos cazuelas de cobre donde se repartía la comida a las enfermas y en un escaparate grande se guardaban los dulces y pasas.

En el siglo XVIII, la sala de san Pedro tenía objetos fijos que ya no se trasportaban al mudar de estación, pues cada piso tenía su propio altar. Así, en la enfermería alta quedó un altar de madera sobre una tarima de pino con sus barandas de granadilla, un frontal

67 ADPS, Libro de autos capitulares (1764-1787), leg. 4B, folios 34r (1770) y 113v (1781). Muy raras veces, la enfermería de san Pedro podría recibir a las enfermas incurables, lo que, además, estaba prohibido por reglamento, salvo excepciones cuando los patronos del hospital lo permitían. En estos casos, recibían a mujeres incurables y mujeres ancianas a cambio de alguna donación, como una casa. Por ejemplo, en 1770 Josepha Álvarez, de sesenta años, vecina de Sevilla y soltera, declarada incurable, se ubicó en una cama de la enfermería y no en la de incurables. Donaba a cambio una casa. En 1781, se recibió a Isabel de Escobar, en separación del común de las enfermas, pagando por ello tres reales de vellón diarios. De esta manera, a finales del XVIII, se mencionan a las "enfermas de costo", las que pagaban de cuatro y medio a seis reales por día, pudiéndose quedar en el hospital el tiempo que desearan. 
de damasquillo, manteles, un retablo, atril, misal y dos candeleros de azófar. Junto al altar estaba una hechura grande de Cristo de bulto en su cruz, debajo de un sitial de brocatel antiguo con un velo de tafetán. Una figura de bulto o hechura de Cristo en su cruz, debajo de un sitial de brocatel antiguo con un velo de tafetán sencillo. Al lado del altar estaba una taquilla en donde se guardaba el vaso del santo óleo. También estaba el sobrepelliz y la estola que utilizaba el cura para administrar a las enfermas. Veintitrés cuadros entre grandes, medianos y pequeños de diferentes devociones y retratos de reyes para adorno del altar estaban colgados en las paredes. Había una imagen pequeña de vestir de la Señora del Rosario con dos camisas, enaguas blancas, vestido de raso encarnado y blanco con encaje de oro y una corona de plata imperial con rayos y manto de tafetán blanco con cuentas de seda cruda y otros dos vestidos viejos, uno morado y otro de colores. El altar de la enfermería baja tenía una cruz de madera de granadillo con estrado, así como una taquilla con su vaso de plata y una tarima y colgaba en la pared un cuadro grande de Jesucristo con la Virgen y san Juan Evangelista. Faroles, velones de bronce alumbraban ambos altares.

La habitación que se usara fuese del bajo o alto era amplia al haberse desalojado a las agonizantes e incurables que habían sido trasladadas a otras salas. En las paredes había dieciocho camas de madera con pies de hierro, con treinta y seis colchones, sábanas, almohadas y paños blancos para las enfermas, además de las camas de la madre enfermera y su ayudante. Estas camas estaban separadas por catorce banquillos de pino. Esta sala tenía un escaparate cerrado donde las cosas necesarias para las enfermas eran guardadas, además de tres cajones. Uno grande que servía de contador para repartir las comidas, otro mediano sobre el que se ponían las medicinas; otro más pequeño para sacramentar. Otra característica era que había muchas sillas, pues el administrador y otras autoridades que trabajaban en el hospital tenían que estar presentes durante las comidas, por eso había una silla grande de cuero antiguo donde se sentaba el administrador, un taburete, una silla de costillas, dos silletas de paja una grande y otra ordinaria. En una esquina estaba un bufete de pies fijos medianos, con un cajón con su chapa y llave donde se guardaba el libro de entradas de enfermas y las tablillas de las comidas y cenas. El médico y el sangrador utilizaban un plato grande, un jarro de peltre y toallas para lavarse y secarse las manos. Había un banquillo de escritorio del médico y tres sillas grandes, la una muy antigua, donde se confesaban las enfermas ${ }^{68}$.

\section{CONCLUSIONES}

El Hospital de las Cinco Llagas, mejor conocida como la Sangre de Sevilla fue uno de los hospitales más grandes e importantes de la España del Antiguo Régimen. Un hospital fundado por fondos privados, pero administrado por los priores de tres conventos sevillanos, se especializó en atender a enfermas que no tuviesen enfermedades incurables, lo que le llevó a contratar a mujeres para su atención y cumplir con las prescripciones médicas.

El área de enfermería femenina del Hospital de las Cinco Llagas se fue configurando paulatinamente con el tiempo. En un comienzo la matrona se encargaba de la atención de las enfermas, pero pronto aparecieron las primeras enfermeras, llamadas madres, que dirigían a criadas en la atención al enfermo. En 1559, el hospital fue trasladado del centro de Sevilla a un edificio renacentista extramuros de la ciudad. Al aumentar la infraestructura aumentó el número de enfermas y esto llevó a organizar mejor la atención de las enfermas.

68 ADPS, Libro de inventario de bienes muebles del Hospital de la Sangre de Sevilla, leg. 1A, folios 273-274 (1636), 110-111 (1699) y 279-280 (1726). 
Uno de los problemas más acuciantes era que las criadas no se mantenían en sus puestos. Una estrategia para mantener a las mujeres en sus puestos fue ofrecerles dotes para tomar estado de matrimonio. A partir de 1587, el hospital empezó a entregar dotes a las criadas que trabajaban en el hospital por más de tres años consecutivos. Con esta medida se trató de retener a las jóvenes para atender a enfermas por la sencilla razón de que más tiempo estuviesen retenidas en sus puestos estaban más preparadas en el oficio del cuidado.

También se debe tener presente el papel fundamental que cumplieron los médicos que trabajaron en el área de medicina de este hospital. Muchos de ellos fueron excelentes profesionales, con amplia experiencia, cuyas indicaciones permitían a las mujeres que trabajaban allí atender adecuadamente a las enfermas. Médicos de la talla de Martín López de la Cueva, Miguel Melero y Antonio de Santaella González trabajaron en el hospital. Incluso el afamado Bartolomé Hidalgo Agüero ejerció en el hospital como médico y cirujano por algunos años. 